\title{
THE HUMAN RESOURCES CONTRIBUTION TO SOCIAL RESPONSIBILITY AND ENVIRONMENTAL SUSTAINABILITY: EXPLORATIONS FROM IBERO-AMERICA
}

J.M. Alcaraz, L. Susaeta, E. Suárez, C. Colon, Gutiérrez, I., Cunha, R., F. Leguizamón, S. Idrovo, N. Weisz, M. Correia, José Ramón Pin 


\title{
THE HUMAN RESOURCES CONTRIBUTION TO SOCIAL RESPONSIBILITY AND ENVIRONMENTAL SUSTAINABILITY: EXPLORATIONS FROM IBERO-AMERICA
}

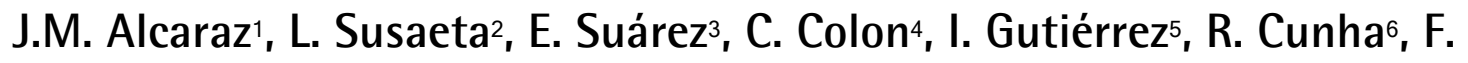 \\ Leguizamón ${ }^{7}$, S. Idrovo ${ }^{8}$, N. Weisz ${ }^{9}$, M. Correia ${ }^{10}$ \\ José Ramón Pin ${ }^{11}$
}

\begin{abstract}
In this paper, we explore the perceptions of human resource (HR) managers on their contribution to social responsibility and environmental sustainability in three Ibero-American countries (Spain, the Dominican Republic and Costa Rica). We rely on a qualitative approach and in-depth interviews at 28 firms in the travel and tourism industry (in the hospitality sector, of particular relevance for these countries and one that has significant sustainability challenges). We examine HR managers' underlying notions about social and environmental issues, stakeholder collaboration, HR practices, roles and internal organization. We outline implications, identify areas of progress and suggest several avenues for HR to advance sustainability-driven agendas.
\end{abstract}

Keywords: HR; Social responsibility; Environmental sustainability; Value creation.

\footnotetext{
1 Senior Lecturer, Murdoch University

2 Senior Lecturer, UCM

3 Professor ESIC

${ }^{4}$ Director, IEBEC

5 Professor, Universidad de Las Américas

${ }^{6}$ Senior Lecturer, Universidade Nova de Lisboa

7 Professor, INCAE

8 Research Director, INALDE

9 Professor, IAE

10 Senior Lecturer, Universidade Nova de Lisboa

11 Professor of Managing People in Organizations and Business Ethics José Felipe Bertrán Chair of Governance and Leadership in Public Administration IRCO - International Research Center on Organizations, IESE
} 


\section{THE HUMAN RESOURCES CONTRIBUTION TO SOCIAL RESPONSIBILITY AND ENVIRONMENTAL SUSTAINABILITY: EXPLORATIONS FROM IBERO-AMERICA}

\section{Introduction}

The field of human resource management (here HRM or, simply, HR) is experiencing an increasing prevalence of debates on the contribution that the discipline is making or should make to social and environmental responsibility (SHRM, 2010, 2011). The notion of the "triple bottom line" (Elkington, 1994) whereby firms should pursue simultaneously economic, social and environmental objectives has often been equated with "sustainability" and seems to be nurturing many of those debates, although it is the social and environmental dimensions that have received a "fresh" new examination in recent years (Taylor, Osland and Egri, 2012).

Among the first to link these fields in depth, Wilcox (2006) outlined several arguments to support the idea of HR as a key element of corporate social responsibility. Lee (2010) has argued that HR needs "to reach out to communities and societies." For McGuire (2011: 508), HR experts "can play an important role in reminding organizations of their social and moral responsibilities." HR practices are crucial to attracting and retaining employees who will drive sustainability, giving them incentives to do so (NBS, 2010). Haugh and Talwar (2011) have claimed that those in charge of people-management practices are well positioned to facilitate learning about social and environmental issues: designing, implementing and monitoring codes of conduct, establishing impact measures, helping to design company structures and policies on sustainability, working with supply chain initiatives that foster human care, facilitating communication and helping to design employee volunteering initiatives that support community involvement. HR can offer productive tools for dealing with environmental change and social challenges through knowledge-sharing practices and transformative learning that can help individuals and organizations adjust their patterns of thinking and behavior (McGuire and Garavan, 2010). For these authors, HR needs to educate the next generation of practitioners and leaders to be mindful of ecological, environmental, social and human issues in developing policies, practices and procedures. 
Common to many of these claims is the underlying assumption that because "the prime focus and skills of HR professionals include organizational process, change management and culture stewardship, they should take a leading role in developing and implementing a sustainability strategy" (SHRM, 2011). Studies of HRM have often taken a normative stance, claiming that HR has "a central role in the search for sustainable organizations" (Jabbour and Santos, 2008) and that corporate social responsibility (CSR) and HR have to establish "a necessary partnership for advancing responsible business practices" (Cohen, 2010).

The purpose of this exploratory, qualitative, interview-based study is precisely to contribute to this debate through an empirical, exploratory examination of the perceptions of human resource (HR) managers concerning their contribution to social responsibility and environmental sustainability (here, for reasons of brevity, we often use the abbreviation "SR/ES"). Our research was carried out in three Ibero-American countries that have received limited scholarly attention: Spain, the Dominican Republic and Costa Rica. The Ibero-American states (the Portuguese and Spanish-speaking nations of the Americas and Europe) show significant commonalities in their institutional, social and macroeconomic contexts (Vassolo, De Castro and Gomez-Mejia, 2011). We focused on the travel and tourism industry (in the hospitality sector, of particular relevance for the three countries mentioned and one that has significant sustainability challenges; see Mowforth, Charlton and Munt, 2008). In the three nations where we undertook our research, travel and tourism represent a significant percentage of the GDP, the national workforce and monetary inflows. (Table 1 shows key indicators reflecting this industry's role in the three nations, plus other country data.)

\section{Table 1}

\section{Data on the Travel and Tourism industry of Spain, the Dominican Republic and Costa Rica}

\begin{tabular}{|c|c|c|c|}
\hline Country Data on Travel and Tourism and Hospitality & Spain & The Dominican Republic & Costa Rica \\
\hline Population (millions), World Bank (2013) & 46.6 & 10.4 & 4.9 \\
\hline Surface area (square meters, thousands) (World Bank, 2013) & 505,6 & 48,7 & 51,1 \\
\hline Gross National Income per capita (US \$) (World Bank, 2013) & 29,180 & 5,620 & 9,550 \\
\hline Total Labor Force (thousands) (World Bank, 2013) & 23,554 & 4,633 & 2,299 \\
\hline Unemployment \% (World Bank, 2012) & 25.2 & 13 & 7.6 \\
\hline Country Brand Index Latinoamerica (FutureBrand, 2013) & & 11 & 3 \\
\hline \% Travel and Tourism over Total GDP, 2013 (WTTC 2014) & 15.7 & 15.3 & 12.1 \\
\hline \% Employment over Total Employment 2013 (WTTC,2014) & 15.8 & 14 & 11.5 \\
\hline International tourist arrivals in 2013 (in thousands) (UNWTO, 2014) & 60,661 & 4,690 & 2,428 \\
\hline US \$ (millions) generated by international tourists in 2013 (UNWTO, 2014) & 60,435 & 5,065 & 24,827 \\
\hline Ranking in Environmental Performance Index (Yale University, 2014) & 7 & 75 & 54 \\
\hline Travel and Tourism Competitive Index (World Economic Forum, 2013) & 4 & 86 & 47 \\
\hline Corruption Perceptions Index (2014) & 37 & 115 & 47 \\
\hline Human Development Index ranking (UNDP, 2013) & 27 & 102 & 68 \\
\hline
\end{tabular}

Sources used (2013, 2014, see References list): World Bank, United Nations World Tourism Organization, Egatur (Tourist Expenditure Survey), Hosteltur, FutureBrand Index, Frontur (Survey of Tourist Border Movements), Central Bank of the Dominican Republic, World Travel and Tourism Council, Economic Impact, National Statistics Institute (INE) (Spain), Costa Rica Tourism Board (ICT), World Economic Forum, Hotel and Tourism Association of the Dominican Republic (Asonahores), Central Bank of Costa Rica, United Nations Development Program, and developed by the authors. 
To guide our empirical exploration, we crafted a model, based on Ulrich and Brockbank (2005), Ulrich and Smallwood (2006), Ulrich, Allen, Brockbank, Younger and Nyman (2009) and Ulrich and Ulrich (2010). This model is intended to examine the "HR architecture" that the organizations in our study may be deploying to support and advance social and environmental responsibility, and to answer the following questions: How do HR managers conceive of social responsibility and environmental sustainability? How do they link these to business challenges? How do they foster collaboration with other stakeholders? What roles do they adopt and what internal organization do they put in place?

Answers to these questions constitute the essence of this paper, which is structured as follows. We first outline briefly some of the developments that have taken place regarding the contribution of HR to social responsibility and environmental sustainability. Then we describe our data collection and data analysis strategy. We then present our findings concerning the underlying notions and involvement of HR departments in relation to social and environmental challenges, stakeholder collaboration, HR practices, roles and internal organization. We identify key differences between "active" and "advanced" firms, and among the three countries. Finally we discuss these findings in the light of current literature and conclude by outlining key implications and areas in which HR can advance sustainability-driven agendas.

\section{Human Resources in the Quest for a Firm's Social Responsibility and Environmental Sustainability}

Two recent and influential reports from the Society of Human Resource Management (SHRM, 2010, 2011), one taking stock and the other presenting a comprehensive survey, have been considered to be seminal documents outlining multiple avenues in which HRM can engage with multiple stakeholders. The reports use a variety of HR practices (e.g. attraction, selection, training, development, compensation, communication, etc.) to create "sustainable organizations."

As reflected in both documents, HRM scholarly work aiming to foster corporate social responsibility has now explored all kinds of topics. HR practices can be used to foster diversity and inclusion, equity, well-being and work-life balance (Fenwick and Bierema, 2008; Jabbour and Santos, 2008; Cohen, 2010), human health and mortality (Pfeffer, 2010) and responsible leadership (Gond, Igalens, Swaen and El Akremi, 2011). HRM can take ownership of multiple dimensions within international reporting certifications (e.g., the Global Reporting Initiative) and human rights frameworks (SHRM, 2011). An abundant stream of literature has dealt with the relationship between employee motivation, work practices, social responsibility and financial performance (a relationship that has been found to be significantly positive by Martínez-del-Río, Céspedes-Lorente and Carmona-Moreno, 2012). Although it can be argued that some of this "CSR-labelled" HR work is dealing with issues that may have been considered under the "traditional" labels and domains of HRM (e.g., employee well-being, health and safety), such work is giving new momentum to HR's involvement in social issues.

At the same time, HRM scholarly work aimed at fostering environmental sustainability has often been often referred to as "green HRM." Several exhaustive literature reviews (e.g., Renwick and Redman, 2008; Jackson, Renwick, Jabbour and Muller-Camen, 2011; Ehnert and Harry, 2012) have shown the multiple "points" at which employees may be involved in environmental-related activities. This rich work has highlighted the role that HRM can have 
in creating environmental awareness and behavioral change (e.g., toward energy and water reduction, transport-to-work practices, procurement policy, carbon emissions limits, etc.: Cohen, 2010). The variety of topics discussed is certainly high: cognitive-affective processes that may support employees' environmental behaviors (Zoogah, 2011), the double environmental dimension that needs to be considered (at work and at home) by employers and employees (Muster and Schrader, 2011), the potential of training and organizational learning to support environmental agendas (Wagner, 2011; Vidal-Salazar, Cordón-Pozo and FerrónVilchez, 2012; Pless, Maak and Stahl, 2012), the inclusion of performance criteria in the design of executive compensation schemes (Berrone and Gomez-Mejia, 2009) or in the design of middle-level managers' compensation (Kimberly, Merriman and Sen, 2012). Interestingly, Delmas and Peković (2013), focusing on organizations as the unit of analysis in a study of the relationship between environmental performance and competitive advantage, found that firms that adopted environmental management standards also reported significantly higher labor productivity (compared with those firms that did not adopt such standards) and the authors pointed out that the adoption of environmental management standards could be associated with greater employee commitment.

Recent years have seen significant development around people-management practices and their potential to embed sustainability into the organizational culture and identity (Bertels, Papania and Papania, 2010; Howard-Grenville, Bertels and Lahneman, 2014). The work by DuBois and DuBois (2012) was also among the first to outline a comprehensive strategic HRM framework in this direction.

Recent literature has highlighted the need to understand the involvement of HR managers and their roles in corporate sustainability agendas, pursuing the debate through such intriguing questions as whether or not HR managers are typically "strategic leaders" or "passive observers" (Harris and Tregidga, 2012). Other authors have claimed there is an urgent need to explore and align the efforts of HR managers with those of environmental sustainability managers (Guerci and Pedrini, 2014).

\section{A Framework to Evaluate the Architecture of HR for Delivering Value to the Social and Environmental Agenda}

In this paper, our main aim is to explore the key tenets of an "HR architecture" to deliver value, as these have been outlined by Ulrich and Brockbank (2005), Ulrich and Smallwood (2006), Ulrich, Allen, Brockbank, Younger and Nyman (2009) and Ulrich and Ulrich (2010). These authors have argued that several dimensions are crucial in determining whether HR can deliver value to the organizations for which it works: understanding the external business realities, aiming to deliver value to multiple stakeholders (both internal and external), prioritizing HR practices (e.g., in relation to recruitment and talent management, and training, development and compensation plans) that will deliver the highest impact for these stakeholders, and putting in place an HR organization and roles capable of orchestrating all this.

In this paper, we assume that these should also be essential dimensions to be explored if HR aims to create value for the social and environmental agendas of the firms its serves (see Figure 1). Our empirical exploration is based on this adapted model and is an attempt to map this out in the context of the three countries and specifically in their travel and tourism (hospitality) industries. 


\section{Figure 1}

HR's Potential to Create Value for Social Responsibility and Environmental Sustainability (Adapted from Ulrich \& Brockbank, 2005; Ulrich \& Smallwood, 2006; Ulrich, Allen, Brockbank, Younger and Nyman, 2009; Ulrich \& Ulrich, 2010)

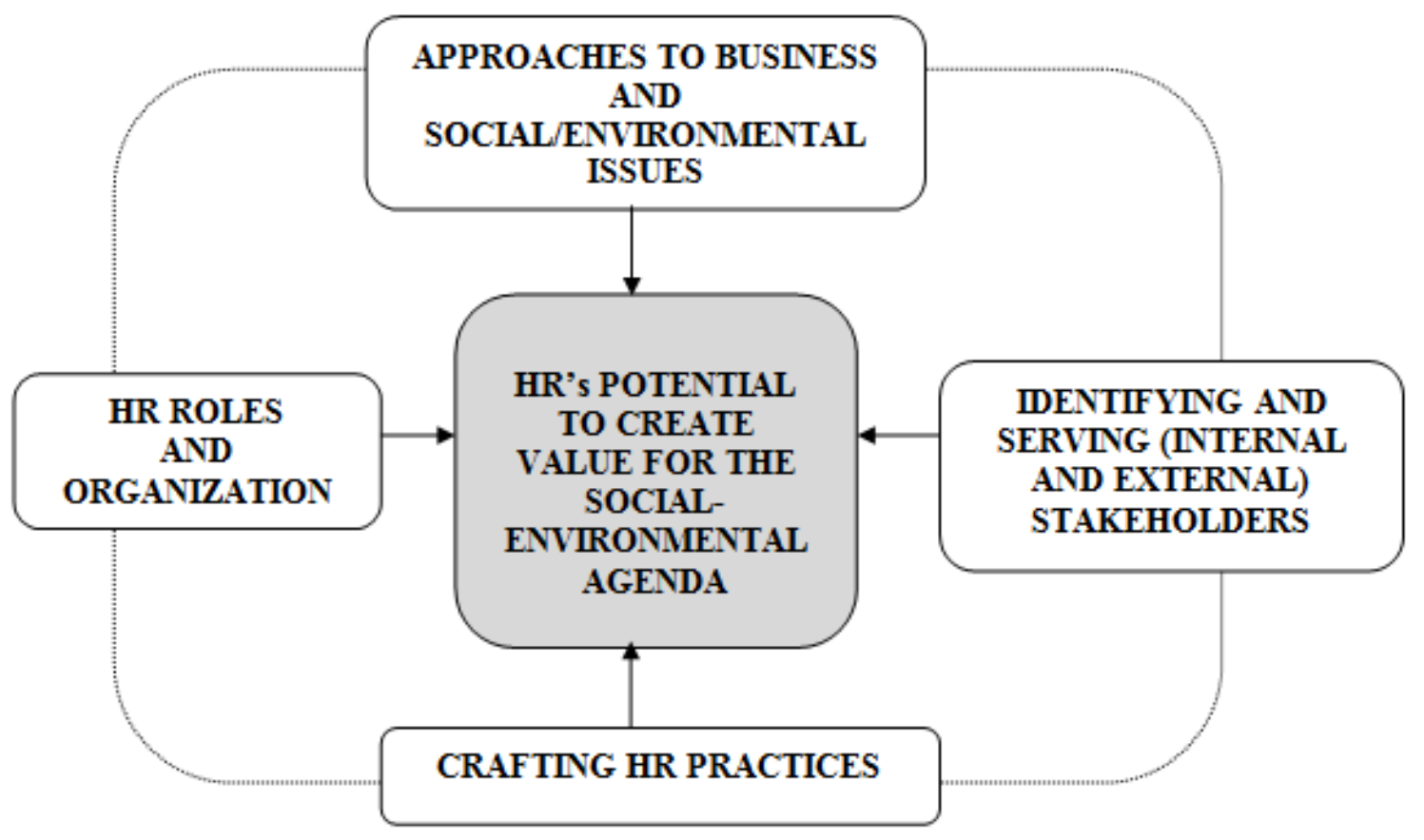

\section{Empirical and Analytical Approach}

Data collection: This research relies on qualitative, semi-structured and in-depth interviews at 28 firms (in the travel and tourism industry, particularly in the hospitality sector) in the following three countries: Spain, the Dominican Republic and Costa Rica.

In each of these organizations we held several interviews, one with the most senior manager dealing with HR and another one with the person in charge of social responsibility and/or environmental sustainability (when these were not directly the responsibility of the HR staff). A total of 36 interviews were held: 13 in the Dominican Republic, 13 in Spain and 10 in Costa Rica. Twenty-six of these were held with HR staff, one with a marketing executive and the rest with personnel holding social and environmental-related positions. (See Table 2 for details; names have been anonymized.) 
Table 2

Companies of this study (names have been disguised to secure anonymity)

\begin{tabular}{|c|c|c|c|c|c|c|c|}
\hline Hotel's name & Interviews held in & Firm's origin & Operations & Profiles Interv. & Type & Size & Evidence of SR/ES Commitment \\
\hline NuevaHosp & Spain & USA & Intl & HR & Urban & $<250$ & Green Key Awards \\
\hline Paraisos & Spain & Spain & Intl & $\mathrm{HR} \& \mathrm{CSR}$ & Beach-City & $>250$ & Green Globe \& EarthCheck Certification, National Environmental Reward \\
\hline Bellevs & Costa Rica & USA & Intl & $\mathrm{HR}$ & City & $<250$ & Certification in Sustainable Tourism, Blue Flag Ecological Program Recognition \\
\hline Uniones & Costa Rica & Costa Rica & Loc & $\mathrm{HR}$ & Rural & $<50$ & Certification in Sustainable Tourism, Member of Cayuga Sustainable Luxury Hotels \\
\hline Carolina & Costa Rica & Costa Rica & Loc & HR \& Sust. & Rural & $<50$ & Certification in Sustainable Tourism, Blue Flag Ecological Program Recognition \\
\hline Berrores & Dom. Rep. & Dom. Rep. & Loc & HR \& Sust. & Beach & $<250$ & Caribbean Gold Coast Award \\
\hline Mjis & Dom. Rep. & Spain & Intl & HR \& Sust. & Beach & $<250$ & Blue Flag Certification, Crystal Apple \& Golden Apple Awards \\
\hline Doles & Spain & Spain & Intl & HR \& Sust. & Beach & $>250$ & Green Globe Certification, ECPAT \& World Code of Ethics of WTO \\
\hline Nuevo Hotel & Spain & Spain & Intl & CSR & Beach & $>250$ & ISO 14001 Certification, Member of The Code ECPAT \\
\hline Viejos & Spain & USA & Intl & $\mathrm{HR}$ & City & $>250$ & ISO 14001:2004 Certification, Sustainability Report, Unicef Partner Award \\
\hline Genelos & Spain & Spain & Intl & $\mathrm{HR}$ & Urban & $>250$ & ISO 50001 \& ISO 14001 Certification, Green Key Certification, GRI A+ \\
\hline Pedrosa & Dom. Rep. & Spain & Intl & $\mathrm{HR}$ & Urban & $<250$ & ISO 14001 Certification, Biosphere Certification, EMAS European Regulation \\
\hline Canteras & Dom. Rep. & Dom. Rep. & Loc & $\mathrm{HR}$ & Beach & $>250$ & Partnerships for Social Development Initiatives \\
\hline Dorotea & Dom. Rep. & USA & Intl & $\mathrm{HR} \& \mathrm{CSR}$ & City & $>250$ & LEED Certification, Member of Hospitality Sustainable P. Consortium \\
\hline Verdes & Spain & Spain & Intl & $\mathrm{HR}$ & Beach-City & $>250$ & ISO 14001 Certification, Biosphere Certification, EMAS European Regulation \\
\hline Nuevas Horas & Spain & Spain & Loc & $\mathrm{HR}$ & Beach & $>250$ & Travelife Gold Award \\
\hline Remeros & Costa Rica & USA & Intl & HR \& Sust. & City & $>250$ & Sustainability Report, LEED Certification, Partnerships for Sustainable Development \\
\hline Pedrerosa & Dom. Rep. & Spain & Intl & $\mathrm{HR}$ & Beach & $>250$ & Blue Flag \& Green Globe Certifications \\
\hline Hospitalidades & Costa Rica & USA & Intl & Mkt \& Sales & City & $<250$ & Certification in Sustainable Tourism \\
\hline Romeros & Spain & USA & Intl & HR \& Sust. & City & $<250$ & Sustainability Report, LEED Certification, Partnerships for Sustainable Development \\
\hline Azules & Costa Rica & Costa Rica & Loc & $\mathrm{HR}$ & Beach & $<250$ & Certification in Sustainable Tourism \\
\hline Playas Nuevas & Costa Rica & USA & Intl & $\mathrm{HR}$ & Beach & $>250$ & ISO 14001:2004 Certification, Sustainability Report, Unicef Partner Award \\
\hline Dondes & Costa Rica & USA & Intl & $\mathrm{HR}$ & Beach & $>250$ & ISO 14001:2004 Certification, Sustainability Report, Unicef Partner Award \\
\hline Carabelas & Spain & Spain & Intl & $\mathrm{HR}$ & Beach-City & $>250$ & Green Globe \& Blue Flag Certifications \\
\hline Dominicos & Dom. Rep. & Spain & Intl & $\mathrm{HR}$ & Beach & $>250$ & Sustainability Report, Great Place to Work Award \\
\hline Nueva Guia & Dom. Rep. & USA & Intl & $\mathrm{HR}$ & City & $>250$ & Sustainability Report, ISO 14001 \& 50001 Certifications \\
\hline Parques & Dom. Rep. & Spain & Intl & $\mathrm{HR}$ & Beach & $>250$ & Blue Flag Certification \\
\hline
\end{tabular}

6 - IESE Business School-University of Navarra 
In this paper, except where indicated, our analysis focuses mostly on the narratives of the HR executives, although occasionally we introduce some observations by people with other responsibilities when those highlight some relevant aspect of the HR dimension. In each country, we conducted the interviews during two stages: initially in 2012-2013 and then a second stage in 2014 that allowed for inquiry refinement and the further exploration of key issues, as these emerged from the first phase. All interviews lasted between one and two hours. Interviews were conducted in Spanish and transcribed verbatim from audio recordings. (The quotes here are translations.) Most transcriptions were offered to the interviewees for their validation.

We selected the firms based on their demonstrated commitment to social and/or environmental issues, using a purposeful sampling logic (Glaser and Strauss, 1967; Patton, 2002). Annual reports and other documentary sources (such as the local press and information from CSR associations) were used as evidence of that commitment. In most cases, these firms were active members of national, regional or global sustainability networks or they had been the recipients of national or international awards recognizing their social and environmental commitment. Others fulfilled one or more of the following criteria: companies listed on the FTSE 100 Index, member companies of the World Business Council for Sustainable Development, members of the International Tourism Partnership, and companies classified as "active" in the United Nations Global Compact directory. Several of these firms have a presence in multiple countries. Companies were chosen so as to include diverse sizes as well as different business orientations within the industry (see Table 2).

Data analysis: Ontologically and epistemologically, ours is an approach that relies on social constructionism, a perspective that recognizes the social and processual nature of human knowledge and its manifestation in texts (spoken or written) (Burr, 2003). The qualitative, in-depth semi-structured interviews are considered from this approach as particularly useful since they allow us to explore the interviewees' accounts as "narratives" - perceptions and rationales that may shape, translate or influence action (van Leeuwen, 2009). A template analysis (King, 2004) was used and three forms were produced in order to agglutinate the data into four key dimensions, as captured in our adapted model (Figure 1), to identify specific HR practices and to "rate" firms. The interview guiding questions were crafted along the following lines: How do HR managers understand the links between business, social and environmental factors and their work? How do they describe their interactions with multiple stakeholders? What are the HR practices to which they refer when they describe their efforts to support the social and environmental agenda of their firms? How do they describe their roles and what are the organizational aspects they highlight? What are the contextual differences they mention that may be particularly salient in their countries?

We followed Guba (1978), Miles and Huberman (1984) and Ryan and Bernard (2003) and their suggested guidelines to identify themes through the recognition of regularities, consistency and commonalities. A coding scheme and iterative process allowed the organization and grouping of emerging themes, a task mainly done by the four first signatory authors of this paper. Inspired by Gond et al. (2010), we also rated each dimension in terms of its apparent sophistication. This resulted in the identification of two broad categories of firms: active and advanced (Table 3). Within our sample, those firms who described ample, compelling and rich activities in each of the four dimensions, outlining clear HR links to business, social and environmental issues, were classified as advanced (seven organizations) while the rest were considered active (21 organizations). The following section presents our main findings. 
Table 3

An evaluation of the sophistication of HR around four dimensions

\begin{tabular}{|c|c|c|c|c|c|c|}
\hline Code & Category & 1. Business and social/environmental approaches & 2. Stakeholders & 3. Grafting HR practices & 4. Internal organization and roles of HR & Mean \\
\hline $\mathrm{H} 01$ & Advanced & 3.00 & 4.88 & 3.83 & 5.00 & 4.18 \\
\hline $\mathrm{H} 02$ & Advanced & 4.00 & 4.13 & 4.38 & 4.25 & 4.19 \\
\hline $\mathrm{HO3}$ & Advanced & 5.00 & 4.38 & 4.50 & 4.75 & 4.66 \\
\hline HO4 & Advanced & 5.00 & 4.63 & 4.83 & 4.75 & 4.80 \\
\hline H05 & Advanced & 4.50 & 3.88 & 3.63 & 5.00 & 4.25 \\
\hline HO6 & Advanced & 5.00 & 4.75 & 3.83 & 3.75 & 4.33 \\
\hline $\mathrm{H} 07$ & Advanced & 5.00 & 4.88 & 5.00 & 4.75 & 4.91 \\
\hline $\mathrm{HOS}$ & Active & 2.75 & 2.88 & 1.29 & 3.25 & 2.54 \\
\hline $\mathrm{HOS}$ & Active & 1.75 & 2.75 & 3.50 & 2.50 & 2.63 \\
\hline $\mathrm{H} 10$ & Active & 2.50 & 2.75 & 2.42 & 2.50 & 2.54 \\
\hline H11 & Active & 4.00 & 3.38 & 3.04 & 3.75 & 3.54 \\
\hline $\mathrm{H} 12$ & Active & 3.25 & 3.25 & 3.17 & 3.00 & 3.17 \\
\hline $\mathrm{H} 13$ & Active & 2.00 & 3.13 & 2.88 & 2.25 & 2.56 \\
\hline $\mathrm{H} 14$ & Active & 3.25 & 3.13 & 3.38 & 2.75 & 3.13 \\
\hline $\mathrm{H} 15$ & Active & 4.00 & 3.17 & 3.50 & 3.75 & 3.60 \\
\hline $\mathrm{H} 16$ & Active & 3.50 & 2.63 & 2.88 & 2.25 & 2.81 \\
\hline $\mathrm{H} 17$ & Active & 1.00 & 1.13 & 1.00 & 1.00 & 1.03 \\
\hline $\mathrm{H} 18$ & Active & 2.50 & 2.00 & 2.00 & 2.25 & 2.19 \\
\hline $\mathrm{H} 19$ & Active & 1.00 & 2.38 & 1.00 & 1.25 & 1.41 \\
\hline $\mathrm{H} 2 \mathrm{O}$ & Active & 1.00 & 1.00 & 1.00 & 1.00 & 1.00 \\
\hline H21 & Active & 2.00 & 1.88 & 2.13 & 1.50 & 1.88 \\
\hline $\mathrm{H} 22$ & Active & 2.50 & 2.75 & 2.96 & 1.00 & 2.30 \\
\hline $\mathrm{H} 23$ & Active & 1.50 & 1.13 & 2.00 & 1.00 & 1.41 \\
\hline $\mathrm{H} 24$ & Active & 1.75 & 1.00 & 1.00 & 1.00 & 1.19 \\
\hline $\mathrm{H} 25$ & Active & 1.75 & 2.50 & 2.00 & 1.50 & 1.94 \\
\hline $\mathrm{H} 26$ & Active & 1.75 & 2.50 & 2.50 & 2.25 & 2.25 \\
\hline $\mathrm{H} 27$ & Active & 1.75 & 2.00 & 2.00 & 2.00 & 1.94 \\
\hline $\mathrm{H} 28$ & Active & 1.00 & 1.50 & 1.50 & 1.50 & 1.38 \\
\hline
\end{tabular}

\section{Findings}

In order to understand HR's potential contribution to key aspects of the social and environmental agenda in the organizations where we conducted interviews, we organized our findings around the model presented in Figure 1. All names and quotes have been anonymized.

\subsection{Dimension I: Approaches to Business and Social/Environmental Issues}

We identified three essential approaches:

A philanthropic approach. Here social responsibility and environmental sustainability (SR/ES) actions are conceived by HR managers as having essentially an altruistic purpose (monetary donations, employees volunteering time, goods, etc.). Often these seemed to be scattered, isolated initiatives ("After the earthquake we sold ice cream in order to obtain money for the community”) (H10).

Social responsibility and environmental sustainability as "efficiency maximizers." In this segment, HR is oriented toward supporting employees in the quest to generate economic savings in some part of the firm's operations. In its environmental dimension, we found the most common to be savings in energy consumption, water savings, oil recycling, etc. 
Strategic orientation. Mostly within the advanced group of firms, HR managers made frequent linkages in our interviews between internal HR practices and those that were external (economic, social and environmental). Here HR was conceived as having a significant role to play. These were the HR managers who would refer in depth to the challenges of the industry (tourism and hospitality), as well as the key social and environmental issues affecting it. They would refer to rising trends, such as "the increasing coastal erosion and the disappearing coral reefs that have devastating effects on our beaches" (H06) or the increasing trend whereby "guests select certain hotels to stay at because they are green hotels" (H27). These managers would frequently relate the precise ways in which environmental issues are (or may be) affecting key activities of the hotel's operations in the long run. For these participants, SR/ES "constitutes a crucial dimension of the strategy, a central element of our business" (H03).

As reported by our participants, several organizational factors would drive or at least heavily influence HR's involvement in the social and environmental agenda. We describe them as having an outside-in or an inside-out orientation.

Outside-in focus: (a) complying with laws, rules and regulations - here firms were essentially committed to comply with national legislation and with the requirements of tour operators or more frequently with those of certifying agencies ("well, it is not that you are going to sell more because you are certified [...] The thing is that you will stop selling because you are not certified" (H09); (b) taking advantage of new market opportunities ("carrying out social actions is good from the point of view of social responsibility, but it also helps us to do business") (H11).

Inside-out focus: (a) morally driven initiatives. In this segment, HR managers commented on the need to "give back to society part of the benefits obtained by the firm, beyond just creating employment or complying with the law"; (b) firm's identity. This was a common element in firms categorized as advanced but seemed also a nascent trend in the group of active firms. The following lines capture this: "We market ourselves as a socially responsible, nationally and internationally recognized hotel [...] The fact that a guest comes because he or she is interested in our project is, precisely, part of our identity" (H05).

\subsection{Dimension II: Identifying and Serving (Internal and External) Stakeholders}

Our findings highlighted mainly three types of interactions around social and environmental initiatives, between HR and several other stakeholders (Figure 2). 
Figure 2

HR's interactions with stakeholders (internal and external)

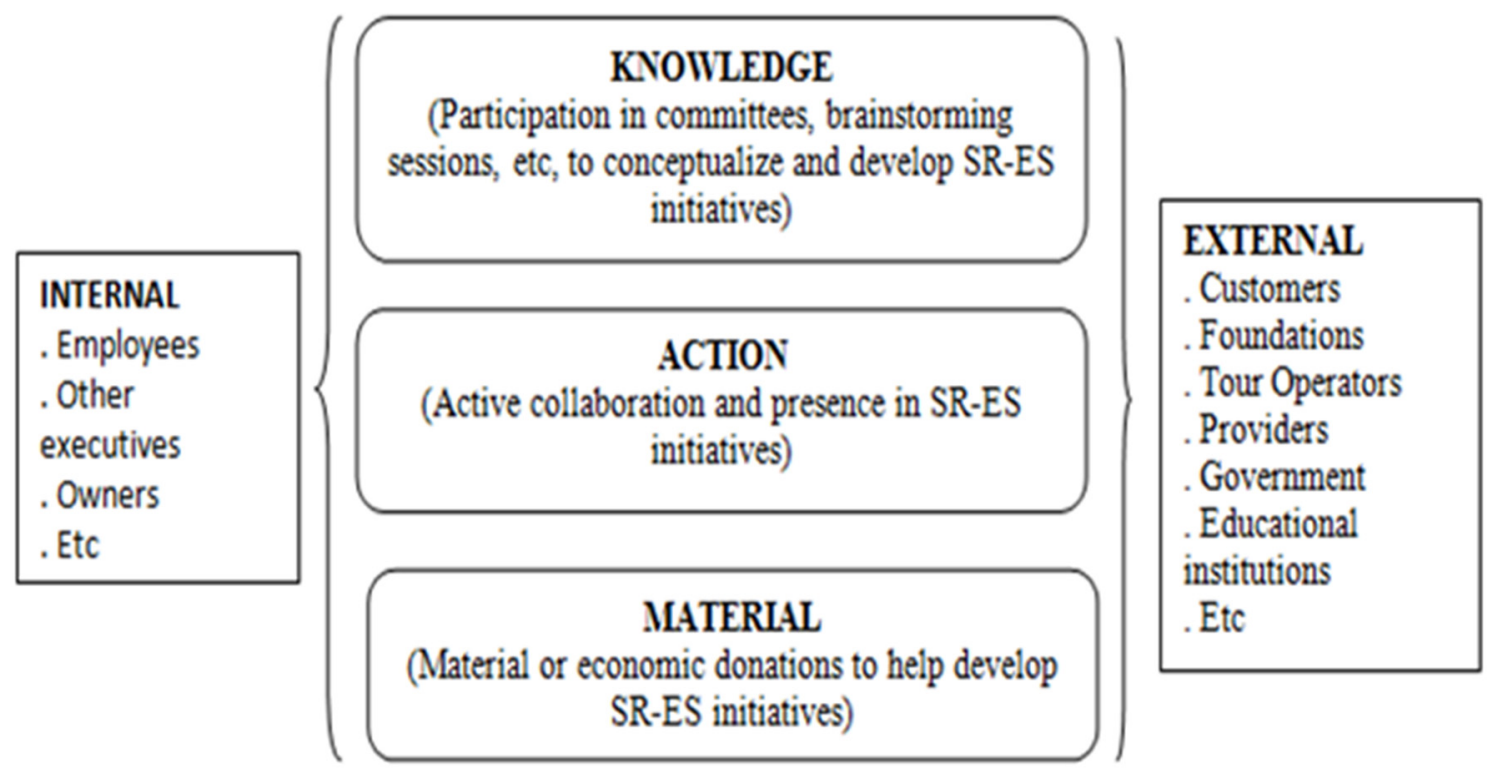

(a) Knowledge-based interactions. Here HR directors would get involved with several other stakeholders in order to generate ideas and solutions. Some of these interactions relied on internal interdepartmental committees. Others involved competitors in the industry: "Each month the committee meets with HR members of different hotels, then we share common and good [social and environmental] practices" (H14).

(b) Action-based interactions. Here HR participants reported involving internal stakeholders (such as employees and other executives) and external ones (e.g., customers, other hotels, foundations and the nearby community) for long-term comprehensive programs, such as those pursuing capacity building (e.g., technical training for targeted populations, such as young vulnerable women). But more often they referred to discrete, occasional activities pursuing what we would describe as "one-shot" results ("organizing a cleaning day with the community and nearby hotels" (H16).

(c) Materially based interactions. Here hotels offered economic support (donations, investment, sponsorship, etc.), tangible goods (food, beverages, medicine, construction materials, education items, etc.). Sometimes the hotel would act as a mediator, distributing the goods provided (e.g., from guests, providers or the employees themselves) to other external social/environmental causes.

Usually we found a combination of these three types of interactions between HR and several other stakeholders. Certainly, at one extreme, HR seems to interact almost exclusively with employees, since SR/ES initiatives require their participation. At the other extreme, HR shows a proactive participation with a truly wide spectrum of stakeholders, proactively reaching social or pro-environmental groups, creating new associations, championing industry forums, etc. 


\subsection{Dimension III: Crafting HR Practices}

Following the framework of Ulrich and Brockbank (2005), we organized our findings around their "menu" of choices concerned with the people, performance, information and work dimensions of HR practices. To these we added "involvement in social issues" and "involvement in environmental issues."

People

Induction. In less than 30\% of our interviews, participants reported explicitly that they included some aspects of SR/ES in their induction initiatives. Intriguingly, on a few occasions we found that our research questions would trigger some reflection ("now that you ask, I am going to take this as something to introduce in our induction programs”) (H13).

Recruitment and selection. Similarly, around 30\% of our participants mentioned including specific aspects of social responsibility and/or environmental sustainability in their recruitment and selection processes ("we measure the candidate's awareness of social responsibility issues") (H19).

Training: Around 80\% of the participants claimed to have had some type of training for SR/ES. According to their accounts, training was often used to "build awareness." Several managers also made comments about helping employees at work so that knowledge and behaviors would be transferred "to their own homes and when educating their kids" (H06).

Motivation. According to most of our participants, social and environmental issues are extremely helpful "to motivate and retain employees" (H02). In their view, these issues help to build engagement and a sense of belonging in the employee.

\section{Performance}

Performance. Less than 50\% of our HR participants claimed to have clear, comprehensive performance management policies tied to SR/ES. Many of our participants referred to the presence of "some items aimed at measuring SR/ES in the employee performance." Often these items seemed to be stuck onto the guidelines established by the headquarters or by tour operators or, more often, by certifying agencies. Our HR managers would report using performance items to create "awareness of and contributions to the firm's social and environmental objectives" (H15). But mostly these would seem to be "loose," sporadic, isolated performance measures, rather than the translation of well-articulated policies into employees' performance reviews or development plans. The following sentence reflects what we often encountered: "I cannot say yet that we have impact indicators [...] We are working on that. We are aware that, at the end of the day, indicators do speak" (H13).

Compensation management. In the majority of cases, we were told things along the following lines (H05): "the results of performance assessment are not yet linked to salary (we will do this in the future)." So, we found that the linking of compensation to social or environmental performance was claimed to be used only by a few of our organizations (all in the advanced category but not even all of them). For this minority, "the performance results [on social and environmental issues] do affect directly the variable compensation of the employee" (H11). 


\section{Information}

External communication. The majority of our participants commented on the possibilities provided by social responsibility and environmental sustainability to "help the firm become a trustworthy one" (H12) or "make ourselves known in the market" (H08). To do so, some of our participants reported establishing a significant presence on social media and participating in external activities linked to SR/ES ("we work with foundations, participating in interinstitutional forums, etc.” (H12).

Internal communication. Several HR managers reported along the following lines: "In HR we need to make sure that this information reaches people and that everybody has the same understanding" (H18). In the advanced hotels, our participants reported using a broader mix of communication tools (murals, e-mail, intranet, internal magazines, meetings, posters in employees' common areas) and a clear purpose to "use communication internally to foster a sense of belonging" (H03).

\section{Work Design}

Our hotel sample had already been selected because of our researchers' evidence that these organizations had internal mechanisms to engage with SR/ES, so most would report having some dedicated items in the organizational and HR processes. Again these items responded mainly to certifying requirements and, to a lesser extent, to strategic plans established by the headquarters ("the strategic plan of social responsibility has the purpose of integrating CSR into the group policies and at all levels of decision making") (H09). Participants reported a multiplicity of certifications. ${ }^{12}$

Regarding the allocation of monetary resources, less than 20\% of our HR participants mentioned having fully dedicated and well-defined budgets to support the SR/ES agenda of their firms. Quite often, monetary provision appeared to be irregular and very much dependent on occasional projects or the year's priorities. Only within the advanced hotels group did HR report enjoying annual provisions tied to concrete projects (and less frequently to concrete measurable outcomes).

\section{Involvement in Social Issues}

Education, health and infrastructure were the social areas that most participants (around 60\%) reported focusing their efforts on. Internal employees and the organization's surrounding communities were reported to be these initiatives' usual stakeholders or recipients. Also, most participants reported on efforts to support the local culture (e.g., local craftwork and arts) as part of their social responsibility efforts. Less frequently and only within the advanced group, organizations reported regular efforts to help "micro-entrepreneurs" and local small businesses (e.g., those providing furniture, food, transportation, etc.) (H05). A few hotels reported having social funds - "an amount that we contribute to, depending on the performance of our hotels. This social fund is used for all kinds of [SR/ES] activities" (H07). In a few cases, these funds were made available to other local companies to channel their SR/ES efforts (H04). HR practices (mostly training and communication) were considered crucial to helping organize and create awareness among employees about these kinds of issues.

\footnotetext{
${ }^{12}$ Green Globe Certification, Right Forest, EarthCheck, Blue Flag, Rainforest Alliance, ISO 9001, ISO 14001, GRI, Global Code of Ethics for Tourism, Biosphere, Ecpat, EMAS, Carbon Disclosure Project, United Nations Global Compact and LEED (Leadership in Energy and Environmental Design). In Costa Rica the most widely used certification was the Certification for Sustainable Tourism (CST), supported by the national government.
} 
Involvement in Environmental Issues

According to our participants, recycling and waste management were the environmental activities most commonly undertaken. After these, the focus would usually be on energy savings and water. Most of these efforts appeared to be centered on "eco-efficiency" (Banerjee, 2011). As one participant said, "we have an advantage from an environmental point of view, which is that we are obsessed with cost management, which makes you very obsessed in your consumption control" (H09). Interestingly, some hotels reported seeing themselves as having an important educational and logistics role for the nearby communities: "At no cost, we collect all the rubbish generated by the village. What is more, those who own villas that are not part of the hotel complex but who have built their houses in the surrounding area can bring their rubbish to the one-stop center. We process it and classify it to be recycled and reused" (H05).

\subsection{Dimension IV: Organization and Roles of HR for Engaging With the SR/ES Agenda}

We identified four distinctive roles (Figure 3).

\section{Figure 3}

HR managers' roles in the SR/ES agenda

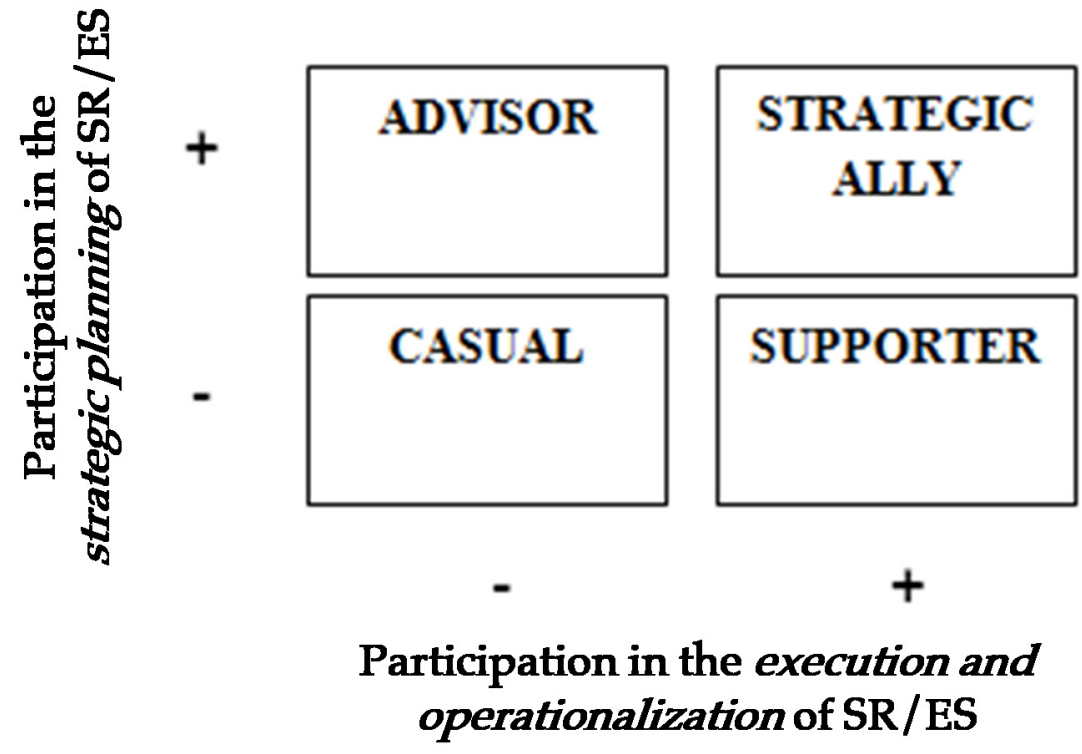

Casual. In this category, essentially observed in a few firms, HR seems to participate only irregularly in the development and day-to-day operationalization of SR/ES (getting involved when the need arises).

Supporter. Around $60 \%$ in our study. In this category, HR is highly involved in the operationalization and execution of SR/ES but has little influence or participation in its strategic shaping ("What HR does is to support, and what I have to do is to search for the people that will work on those initiatives. We provide information and the logistics around the activities that are planned") (H16).

Interestingly, around 60\% of the CSR and/or environmental sustainability experts that we also interviewed reported conceiving of HR managers in their organizations as having essentially this "supporter" role. 
Advisor. In this category, HR "essentially contributes with its own ideas and proposals" (H21) in the definition and development of the SR/ES agenda but with only occasional engagement in the execution. In other words, it offers guidance to other departments on how to move SR/ES forward, essentially from the point of view of employee-related issues.

Strategic ally. In this group, HR participates actively in the key definitional issues relating to the social/environmental agenda, in planning, organizing, developing and implementing that agenda. This seemed to be the case in one third of our organizations ("because HR is like the guide. It is what leads all departments. Depending on their actions, all the staff will be involved”) (H28).

\subsection{Key Differences Between Advanced and Active Firms in This Study}

\section{Table 4}

Key differences between advanced and active organizations in our study

The group of advanced organizations:

- For this group, social and environmental issues are seen as a crucial part of the organization's identity. Here firms have a more integrated approach in which HR efforts seem clearly aligned with the social and environmental issues affecting key dimensions of the business. The roles of advisor and strategic ally were found mostly in this group. In the majority of these hotels, HR managers were also formally responsible for the social responsibility agenda. Here participants reported being particularly concerned with the creation of organizational cultures that would support social and environmental issues at large.

- This group reported a more frequent use of tools to monitor HR efforts. Those in the group also claimed the need for progressive plans to allow them to move from "small wins" to more ambitious projects. They reported putting in place measures to generate knowledge about social and environmental issues and spread it to other levels of the organization (through training, coordination of activities, talks, etc.). They were also clearly trying to generate or implement initiatives locally that could be replicated in other hotels and exported to other countries. "We have created a cultural program to raise awareness among employees. The notion of commitment to work, care and preservation was created here by our HR and then spread everywhere else" (H07).

- This group claimed broader and long-term plans to support the socioeconomic level of the locations and regions where their hotels were established. Here HR assumed a key role in coordinating and "activating" employees.

The group of active organizations:

- Participants in this group reported a variety of (social and/or environmental) initiatives, not always clearly linked to key dimensions or challenges of the business. Priorities, processes and even rationales would not always look fully coherent. "Occasional" activities were more frequent than integrated, systematic approaches.

- Although participants in this group often recognized the need to serve and create value for multiple stakeholders, most efforts would be internally focused, and interactions with stakeholders would be more frequent at the "action" and "material" levels, as described earlier in this paper.

- Often HR activities would be reported as aiming to "create awareness among the employees of social and environmental problems" (H14) and "helping employees feel proud" (H08).

- Participants would report seeing social and environmental pursuits as more dependent on and subject to the firm's "economic moment" (bonanza, crisis, etc.). 


\subsection{Key Differences Between Spain, the Dominican Republic and Costa Rica}

\section{Table 5}

Key differences: Dominican Republic, Spain and Costa Rica

The most precarious scenario was pictured by our participants in the Dominican Republic. Issues reported usually revolved around extremely low levels of education, hygiene and safety. (Several participants reported recommending that guests not "get out of the hotel.") The government was usually characterized as "erratic" and unsupportive of their social and environmental efforts. It is in this country that participants reported high levels of government corruption and low levels of law enforcement (something that seems to coincide with the Corruption Perceptions Index, 2014). The following quote illustrates a degree of frustration commonly reported by many participants in that country: "we have this situation in the malecón [esplanade] in which we have no support from the council. They may come one day to collect the garbage [...] and it may take them another month to come again. Then our beach is full of rubbish." In this country, participants also complained often about the temporary nature of a lot of corporate foreign investment in the hospitality sector. Their perception was that narrow and short-term views were predominant, resulting in limited commitment to the development of local areas.

It was in the Dominican Republic and in Costa Rica that our participants reported greater efforts relating to training and education as the crucial areas to prioritize. Also they reported on the need to extend prosocial and pro-environmental behaviors from the organization to the personal sphere of the employees' lives.

The requirements from certifying agencies seemed to be particularly influential in all three countries. In bigger firms, central headquarters (particularly those from Spain, which were seen as having the strongest power over the subsidiaries) would be reported as having robust and clear implementation and standardizing guidelines. In the three countries and for the smaller hotels, our participants reported seeing the commitment of the owner or CEO as the crucial driver of social and environmental involvement. In these three countries, rural-oriented hotels would seem to have higher levels of environmental commitment. Efforts to save energy were particularly evident in the Dominican Republic, where electricity supply is intermittent and among the most expensive in the developing world (Diario Libre, 2014).

In the case of Costa Rica, the accounts of our participants would reflect a more comprehensive approach to SR/ES, and HR efforts seemed generally more consistent with key perceived business priorities. The Certification for Sustainable Tourism (CST) was perceived as a crucial government-supported driver. Its "transverse" character (differentiating between different hotel categories and sizes) was described as a key factor in what many described as Costa Rica's "sustainability success." Also, internal and external communication with multiple stakeholders appears to be more formal, documented and frequent. The inclusion of customers in the hotel initiatives was often described a "prerequisite" for most organizations: "according to our CST, we have to involve the external customers. They need to experiment and get in touch with nature, the culture, so that they learn. (They are not here merely to relax)" (H04). It was in Costa Rica that participants most often mentioned initiatives to foster "local competitiveness through sustainable development” (H03).

\section{Discussion and Conclusion}

Our essential concern in this research has been to explore current efforts around social and environmental responsibility as these are perceived by HR managers. We have aimed to understand their views on the interaction between social/environmental phenomena and their businesses challenges. We have also attempted to identify the most salient stakeholders they work with, the HR practices they use, and the roles and internal organization that they seem to 
be putting in place for their firms' quest to be sustainable. We have assumed that these are some of the key dimensions of an "HR architecture" that can help to deliver value in organizations pursuing social and environmental responsibility.

Based on our study, we consider that, despite the variety of approaches undertaken by the HR participants interviewed, significant work needs to be done to integrate HR with social/environmental agendas, particularly if these agendas aim to achieve not only short-term but also long-term business, social and environmental challenges (Bansal and Knox-Hayes, 2013). Although the cases of pure rhetoric were a minority in our sample (unlike in other studies, such as Harris and Tregidga, 2014), philanthropic "one-shot" approaches (such as isolated donations) are still, in our view, too frequent and have no evident connection to the core business of many of these firms.

Our findings coincide only partially with those of the survey-based SHRM report (2010b), in which the contribution to society, competitive financial advantages, environmental considerations, saving money on operational costs, and health and safety considerations were listed as the key reasons for HR to get involved in social and environmental agendas. In our study, the contribution to society was often translated into supporting a few stakeholders, financial gains were mentioned only occasionally with significant detail, "eco-efficiency" was a predominant target, and health and safety featured heavily among the HR efforts aimed at supporting essentially internal employees. A careful prioritization of social and environmental causes and their potential to support the business, or to be translated into competitive advantage (Porter and Kramer, 2006), was not always obvious.

It is worth noting that we had already selected our sample from among firms for which we already had some evidence of a commitment to social or environmental issues. Our research shows mixed results, with "advanced firms" leading the way with more engaged views on sustainability, exhibiting firm identities as cultural pillars, undertaking more solid efforts to monitor HR actions and outlining more ambitious goals toward supporting multiple communities. But from these findings we can suggest that it would be beneficial for HR to fully embrace wider notions of social and environmental responsibility, for example, as these are developed in the "triple bottom line" notion (Colbert and Kurucz, 2007) or in the "shared value creation" agenda (Porter and Kramer, 2011). When organizations carefully prioritize social and environmental initiatives that are closely aligned to the firm's core business, the possibility of "creating shared value" (Porter and Kramer, 2011) and making a meaningful impact becomes more likely. This will require the adoption by HR of the more ambitious, engaged and longterm approaches that characterize sustainability (Bansal and Knox-Hayes, 2013).

Regarding HR's engagement with multiple stakeholders, we would suggest that exchanges between HR and stakeholders (especially external ones) need to take a more collaborative, knowledge-sharing, sectoral and interdisciplinary direction. In many of these firms, most efforts had the employee as the only recipient of "social initiatives." Often committees would be constituted by internal members only. Very rarely, they would consist of industry associations or task forces and, even more infrequently, of clusters for local development. However, as has been argued (Porter and Kramer, 2011; Pfitzer, Bockstette and Stamp, 2013), in the quest for social, environmental and economic value, non-"traditional" partnerships (e.g., including forprofit firms, NGOs, competitors, governmental organizations and social entrepreneurs) will be decisive. 
Regarding the $H R$ practices, two findings seem particularly relevant to us. Firstly, we would suggest that the potential of recruitment and talent management (Ulrich and Smallwood, 2006) may be significantly untapped. Very few of our participants outlined detailed recruitment activities dedicated to attracting and then selecting employees that could help shape social and environmental agendas. At the same time, from our findings we would claim that training efforts should be broadened - beyond the frequent goal of raising employees' awareness. If sustainability is to be fostered, training should pursue deep learning and, as such, should affect the cognitive, skills and affective dimensions (Bain, 2004). Training activities may also target diverse groups, beyond the current focus on the internal employee (e.g., those who may have a role in maximizing satisfactory customer experiences). On the other hand, the performance and compensation practices (although used in a very limited way) reveal a crucial finding of this research. The "soft" approach that we found revealed very limited use of performance and other types of indicators and suggests that significant work needs to be done in this area. The following two questions remain crucial: How can HR align performance indicators more closely with social and environmental issues? How can effective compensation plans be put in place to foster this new sustainability agenda? Our findings are similar to those of Harris and Tregidga (2014) and Jackson et al. (2011). The well-known HR wisdom that maintains that "people do what they are rewarded for" and castigates the "folly" of "hoping for A, but rewarding B" (Kerr, 1975) reflects the need to align social and environmental practices with concrete performance and compensation targets as a fundamental direction for HR managers (Berrone and Gomez-Mejia, 2009). For us, it was quite significant that several non-HR participants in our study (particularly sustainability managers) in all three countries vehemently considered the need for HR to become "a much more active agent" and to include performance and compensation management sustainability-related items at all levels of the organization, "not just at the executive level" (H15, sustainability manager).

Interestingly, our participants made no mention of some other people-oriented practices (such as coaching, development, promotion or termination policies) and their potential to help the firm's sustainability agenda. We believe that this should be explored in future research.

Most of our HR participants reported being more dedicated to supporting social vs. environmental initiatives but they saw the increasing relevance of the natural environment. Certainly, integrative HR practices and efforts hold a lot of promise (Guerci and Pedrini, 2014). Also, collaboration between HR and sustainability managers is a vital goal (Guerci and Pedrini, 2014). It is precisely in the area of performance and compensation that we see major opportunities for improvement if HR is to support a social/environmental agenda driven by value creation.

Also, although we certainly perceived efforts to involve the hotel with external communities for example, sourcing from local providers (of food and other goods), recruiting and developing local talent, supporting local schools, arranging diverse environmental initiatives, etc. - we consider that more efforts need to be taken to benefit external communities, a crucial element of a solid sustainability agenda (Mowforth, Charlton and Munt, 2008). On an environmental front, moving beyond employee-related activities, pursuing "eco-efficiency" should be a vital step for HR in order to create meaningful impacts on concrete ecosystems (Banerjee, 2011). Forest protection, coastal and marine protected areas or forest cover are all categories in which the three countries rate low (according to the Environmental Performance Index, 2013) and are increasingly crucial for the survival and flourishing of the industry (UNWTO, 2014). 
Regarding issues around their firm's identity, many of our participants would frequently mention the need to craft HR practices to embed social and environmental issues into the organizational culture. They would often refer to "creating awareness among employees" as the central tool for doing this. We believe, however, that more comprehensive efforts will be needed in this quest. As shown by the Network for Business Sustainability (NBS, 2010), the menu of practices to embed sustainability in organizational culture is certainly ample and may rely on a myriad of practices such as fulfilment practices, formal procedures, innovation practices and informal practices. HR managers have a much broader range of tools available than the ones they seem to be using.

Regarding the $H R$ roles and internal organization put in place by $\mathrm{HR}$, a crucial finding of this research relates to the fact that less than 20\% of the HR participants mentioned having fully dedicated and well-defined budgets for their initiatives related to SR/ES. This suggests that HR may be addressing pro-social and environmental initiatives with limited financial resources. This may challenge HR professionals' capacity to become agents of change and move beyond casual and supporting roles to more advanced ones (such as advisor or strategic ally). In the organizations where we conducted interviews, HR clearly sees the social agenda as part of its job, which confirms a trend noted by Zappalà (2004).

Certainly, if HR aims to become not only a credible partner but one that gets "called upon" to deliver solutions, we believe that familiarization with relevant international practices is vital. In this regard, there are significant differences between the three countries of our research, as indicated in the Travel and Tourism Competitive Index (World Economic Forum, 2013) and reflected in more detail in Table 1. It is in the Dominican Republic where we saw an accentuation of what some researchers have characterized as commonalities of the "Latin American context" (Vassolo et al., 2010) that may hinder sustainability efforts: institutional voids, frequent arbitrary alterations of the "rules of the game," poor regulation of competition, volatility and financial distress affecting the corporate world, etc. According to FutureBrand (2013), the Dominican Republic competes well with Costa Rica on beaches and hotels and resorts (the "tourism" dimension) but has worse valuations in education, the health system, job opportunities, the environment, and heritage and culture. Indicators in the Human Development Index (2013) and in the Corruption Perceptions Index (2014) all depict more favorable images for Costa Rica and, especially, for Spain. But in all three countries, the role of the corporate world in supporting economic, social and environmental causes is crucial. As mentioned by many of our participants in Spain, the current and devastating economic crisis and increasing government corruption have highlighted the weaknesses of governments when it comes to sustaining social and environmental commitments as well as the need for businesses to step in (Escudero and García Lama, 2014).

The exchange of knowledge around best practices and the generation and generalization of ideas with the potential to expand learning (Ulrich and Smallwood, 2006) is an ongoing practice between these three countries (PIMA, 2014). The adaptation and necessary localization of "best practices" seem to be a promising avenue. Also, beyond voluntary adhesions and certifications, the role of mandated, government-led initiatives such as Costa Rica's Certification for Sustainable Tourism (CST) show significant promise. We find particularly relevant the fact that some of the often-defamed "all-inclusive" hotels in this country enjoy the highest standards awarded by this certification. For us, HR needs to be aware of many of these issues since people management practices will affect significantly the results of sustainability efforts (NBS, 2010). 
We believe that one of the key contributions of this paper has been to explore all these issues in the Ibero-American context. But certainly our three-country research, focused on the travel and tourism (hospitality) industry, has dealt with a limited sample of executives' narratives. This research should certainly be complemented by the thorough analysis of other sources (e.g., CSR and sustainability reports, HR and company policy documentation, HR forms, etc.). But in our view, the biggest limitation of this research is precisely captured in the words of Ulrich and Brockbank (2005): "value is defined by the receiver more than the giver." Further research will need to explore the views, perceptions and accounts of those who are the ultimate recipients of HR and organizational efforts: internal and external stakeholders (employees, shareholders, other managers, customers, NGOs, etc.) plus those representing concrete ecosystems. Inputoriented efforts need to be combined with strong output-focused actions that deliver value for those who need the most - not as determined by executives but as perceived by those other stakeholders (Banerjee, 2011). In other words, beyond normative claims that HR is central to sustainability (Jabbour and Santos, 2008), the true value of HR activities - their impact and how those efforts support the social and environmental agenda - will be determined by others. Further qualitatively oriented research will certainly need to explore precisely and in depth the views of those other multiple stakeholders and certainly explore other industries.

To conclude: for us, the fact that in many of the organizations we explored (the "advanced" ones) it was the HR department that was leading the social responsibility initiatives shows significant promise. The fact that HR managers deal directly with key people management practices gives them substantial opportunities to become not merely "passive observers" but "strategic leaders" (Harris and Tregidga, 2014), to serve as a role models who show "courage to challenge" rather than being simply "bystanders" (Parkes and Davis, 2013) and to advance and secure more responsible and sustainable futures. But this important journey has just started. 


\section{References}

Asonahores (Hotel and Tourism Association of the Dominican Republic) (2014) "Turismo en

República Dominicana.” http://www.asonahores.com, accessed December 1, 2014.

Banerjee, S.B. (2007) Corporate Social Responsibility: The Good, the Bad and the Ugly. Cheltenham: Edward Elgar.

Banerjee, B. (2011) "Embedding Sustainability Across the Organization: A Critical Perspective." Academy of Management Learning and Education 10(4), 719-739.

Bansal, T. (2005) "Evolving Sustainably: A Longitudinal Study of Corporate Sustainable Development.” Strategic Management Journal 26(3):197-218.

Bansal, T. and J. Knox-Hayes (2013) "The Time and Space of Materiality in Organizations and the Environment." Organization and Environment 26(1): 61-82.

Bertels, S., L. Papania and D. Papania (2010) Embedding Sustainability in Organizational Culture: A Systematic Review of the Body of Knowledge. Network for Business Sustainability working paper. http://www.nbs.net/wp-content/uploads/dec6_embedding_sustainability.pdf, accessed December 1, 2014.

Berrone, P. and L.R. Gomez-Mejia (2009) "Environmental Performance and Executive Compensation: An Integrated Agency-Institutional Perspective." Academy of Management Journal 52(1), 103-126.

Burr, V. (2003) Social Constructionism. London: Routledge.

Central Bank of Costa Rica (Banco Central de Costa Rica) (2014) "Turismo en Costa Rica." Retrieved from http://www.bccr.fi.cr, accessed December 1, 2014.

Central Bank of the Dominican Republic (Banco Central de la República Dominicana) (2014) "Sector Turismo." http://www.bancentral.gov.do/estadisticas_economicas/turismo, accessed December 1, 2014.

Cohen, E. (2010) CSR for HR: A Necessary Partnership for Advancing Responsible Business Practices. Manchester: Greenleaf.

Colbert, B. and E. Kurucz (2007) "Three Conceptions of Triple Bottom Line Business Sustainability and the Role for HRM.” Human Resource Planning 30(1), 21-29.

Costa Rica Tourism Board (Instituto Costarricense de Turismo) (2014) http://www.visitcostarica.com/ict/paginas/ict.asp?ididioma=1, accessed December 1, 2014.

Delmas, M. and S. Peković (2013) "Environmental Standards and Labor Productivity: Understanding the Mechanisms That Sustain Sustainability." Journal of Organizational Behavior 34(2): 230-252.

Diario Libre (2014) "República Dominicana es el segundo país con la energía más cara del mundo.” $\quad$ http://www.diariolibre.com/economia/2014/07/14/i698721_repblica-dominicanasegundo-pas-con-energa-cara-del-mundo.html, accessed December 1, 2014.

DuBois, C. and D. DuBois (2012) "Strategic HRM as a Social Design for Environmental Sustainability in Organization.” Human Resource Management 51(6): 799-826. 
Egatur (Tourist Expenditure Survey) (2014) "Turismo en España." http://www.iet.tourspain.es/es-es/estadisticas/egatur/paginas/default.aspx, accessed December 1, 2014.

Ehnert, I. and H. Harry (2012) "Recent Developments and Future Prospects on Sustainable Human Resource Management: Introduction to the Special Issue." Management Revue 23(3), 221-238.

Elkington, J. (1994) "Towards the Sustainable Corporation: Win-Win Business Strategies for Sustainable Development." California Management Review 36(2): 90-100.

Escudero, M. and J. García Lama (2014) La responsabilidad social empresarial y la creación de valor en América Latina. Bilbao: Universidad de Deusto.

Fenwick, T. and L. Bierema (2008) "Corporate Social Responsibility: Issues for Human Resource Development Professionals." International Journal of Training and Development 12(1): 24-35.

Frontur (Survey of Tourist Border Movements) (2014) "Estadísticas Turismo en España." http://www.iet.tourspain.es/es-es/estadisticas/frontur/paginas/default.aspx, accessed December $1,2014$.

FutureBrand Index (2014) "FutureBrand Launches the Country Brand Index 2014-15." http://www.futurebrand.com/news/futurebrand-launches-the-country-brand-index-2014-15, accessed December 1, 2014.

Garavan, T. and D. McGuire (2010) "Human Resource Development and Society: Human Resource Development's Role in Embedding Corporate Social Responsibility, Sustainability, and eEthics in Organizations." Advances in Developing Human Resources 12(5): 487-507.

Glaser, B.G. and A.L. Strauss (1967) The Discovery of Grounded Theory: Strategies for Qualitative Research. Chicago, Illinois: Aldine Publishing.

Gond, J.P., J. Igalens, V. Swaen, and A. El Akremi (2011) "The Human Resources Contribution to Responsible Leadership: An Exploration of the CSR-HR Interface." Journal of Business Ethics 98: 115-132.

Guba, E. G. (1978) Toward a Methodology of Naturalistic Inquiry in Educational Evaluation. Monograph 8. Los Angeles: UCLA Center for the Study of Evaluation.

Guerci, M. and M. Pedrini (2014) "The Consensus Between Italian HR and Sustainability Managers on HR Management for Sustainability-Driven Change - Towards a 'Strong' HR Management System." The International Journal of Human Resource Management 25(13): $1787-1814$.

Harris, C. and H. Tregidga (2012) "HR Managers and Environmental Sustainability: Strategic Leaders or Passive Observers?" The International Journal of Human Resource Management 23(2): 236-254.

Haugh, H.M. and A. Talwar (2010) "How Do Corporations Embed Sustainability Across the Organization?” Academy of Management Learning and Education 9(3): 384-396.

Howard-Grenville, J., S. Bertels and B. Lahneman (2014) "Sustainability: How It Shapes and Is Shaped by Organizational Culture" in B. Schneider and K. Barbera (eds.), The Oxford Handbook of Organizational Culture and Climate, 20-42. Oxford University Press. 
Hosteltur (2014) “Noticias de Turismo.” http://www.hosteltur.com, accessed December 1, 2014.

Jabbour, J. and F. Santos (2008) "The Central Role of Human Resource Management in the Search for Sustainable Organizations." The International Journal of Human Resource Management 19(12): 2133-2154.

Jackson, S. E., D. Renwick, C.J.C. Jabbour, and M. Muller-Camen (2011) "State-of-the-Art and Future Directions for Green Human Resource Management: Introduction to the Special Issue." Zeitschrift für Personalforschung 25(2): 99-116.

Kerr, S. (1975) "On the Folly of Rewarding A, While Hoping for B." The Academy of Management Journal 18(4): 769-783.

King, N. (2004) "Using Templates in the Thematic Analysis of Text," in C. Cassell and G. Symon (eds.), Essential Guide to Qualitative Methods in Organizational Research, 47-62. London: Sage.

Lee, M. (2010) "Shifting Boundaries: The Role of HRD in a Changing World." Advances in Developing Human Resources 12(5): 524-535.

Martínez-del-Río, J., J.Céspedes-Lorente, and E. Carmona-Moreno (2012) "High-Involvement Work Practices and Environmental Capabilities: How HIWPs Create Environmentally Based Sustainable Competitive Advantages." Human Resource Management 51(6): 827-850.

McGuire, D. and T. Garavan (2010) "Closing Comments: A Call to Action." Advances in Developing Human Resources, October 2010, 12(5): 614-616.

Merriman, K. and S. Sen (2012) "Incenting Managers Towards the Triple Bottom Line: An Agency and Social Norm Perspective.” Human Resource Management 51(6): 851-872.

Miles, M.B. and A.M. Huberman (1984) Qualitative Data Analysis: A Sourcebook of New Methods. London: Sage Publications.

Miles, M.B. and A.M. Huberman (1994) Qualitative Data Analysis (second edition). London: Sage.

Mowforth, M., C. Charlton and I. Munt (2008) Tourism and Responsibility: Perspectives from Latin America and the Caribbean. London: Routledge.

Muster, V. and U. Schrader (2011) "Green Work-Life Balance: A New Perspective for Green HRM.” Zeitschrift für Personalforschung 25(2): 140-156.

National Statistics Institute (Instituto Nacional de Estadística) (2013) "Coyuntura Turística Hotelera (EOH/IPH/IRSH).” http://www.ine.es/daco/daco42/prechote/cth0714.pdf, accessed December 1, 2014.

NBS (Network for Business Sustainability) (2010) Canadian Business Sustainability Priorities 2011. Working paper.

Patton, M.Q. (2002) Qualitative Research and Evaluation Methods (third edition). Thousand Oaks, California: Sage Publications.

Parkes, C. and A.J. Davis (2013) "Ethics and Social Responsibility - Do HR Professionals Have the 'Courage to Challenge' or Are They Set to Be Permanent 'Bystanders'?” The International Journal of Human Resource Management 24(12): 2411-2434. 
Pfeffer, J. (2010) "Building Sustainable Organizations: The Human Factor." Academy of Management Perspectives 24(1): 34-45.

Pfitzer, M., V. Bockstette, and M. Stamp (2011) "Innovation for Shared Value." Harvard Business Review, September 2011: 101-107.

PIMA (Academic Mobility and Exchange Programme) (2014) "Documento base." http://www.oei.es/pima/doc_base.php, accessed December 1, 2014

Pless, N., T. Maak and G. Stahl (2012) "Promoting CSR and Sustainable Development Through Management Development: What Can Be Learned From International Service Learning Programs?"

Human Resource Management 51(6): 873-904.

Porter, M.E. and M.K. Kramer (2006) "Strategy and Society: The Link Between Competitive Advantage and Corporate Social Responsibility.” Harvard Business Online, December 2006.

Porter, M.E. and M.K. Kramer (2011) “Creating Shared Value.” Harvard Business Review 89(1/2): 62-77.

Ryan, G. and R. Bernard (2003) “Techniques to Identify Themes.” Field Methods 15: 85-109.

SHRM (Society for Human Resource Management) (2010) HRM's Role in Corporate Social and

Environmental Sustainability. Alexandria, Virginia: SHRM.

SHRM (Society for Human Resource Management) (2011) Advancing Sustainability: HR's Role A Research Report by the Society for Human Resource Management, BSR and Aurosoorya. Alexandria, Virginia: SHRM.

Taylor, S., J. Osland, and C.P. Egri (2012) “Guest Editors' Introduction: Introduction to HRM's Role in Sustainability: Systems, Strategies, and Practices." Human Resource Management 51: 789-798.

Ulrich D. and W. Brockbank (2005) The HR Value Proposition. Boston: Harvard Business School Press.

Ulrich, D. and N. Smallwood (2006) How Leaders Build Value: Using People, Organization, and Other Intangibles to Get Bottom-Line Results (first edition). Hoboken, New Jersey: Wiley.

Ulrich, D., J. Allen, W. Brockbank, J. Younger, and M. Nyman (2009) HR Transformation: Building Human Resources From the Outside In. NYC: McGraw-Hill.

Ulrich, D. \& Ulrich, W. (2010) The why of work. New York City: McGraw-Hill.

UNDP (United Nations Development Program) (2014) "Environment and Energy." http://www.undp.org/content/undp/en/home/ourwork/environmentandenergy/overview.html, accessed December 1, 2014.

UNWTO (World Tourism Organization) (2014) Tourism Highlights. dtxtq4w60xqpw.cloudfront.net/sites/all/files/pdf/unwto_highlights14_en_hr_0.pdf, $\quad$ accessed December 1, 2014. 
Van Leeuwen, T. (2008) Discourse and Practice: New Tools for Critical Discourse Analysis. Oxford: Oxford University Press.

Vassolo, R.S., J.O. De Castro, and L.R. Gomez-Mejia (2011) "Managing in Latin America: Common Issues and a Research Agenda." Academy of Management Perspectives 25(4): 22-36.

Vidal-Salazar, M.D., E. Cordón-Pozo, and V. Ferrón-Vilchez (2012) "Human Resource Management and Developing Proactive Environmental Strategies: The Influence of Environmental Training and Organizational Learning." Human Resource Management 51(6): 905-934.

Wagner, M. (2011) "Environmental Management Activities and Sustainable HRM in German Manufacturing Firms - Incidence, Determinants, and Outcomes." Zeitschrift für Personalforschung 25: 157-177.

Wilcox, T. (2006) "Human Resource Development as an Element of Corporate Social Responsibility.” Asia Pacific Journal of Human Resources 44: 184-196.

World Bank (2014) "Population, total.” data.worldbank.org/indicator/SP.POP.TOTL, accessed December 1, 2014.

World Economic Forum (2014) The Travel and Tourism Competitiveness Report 2013. www3.weforum.org/docs/WEF_TT_Competitiveness_Report_2013.pdf, accessed December 1, 2014.

WTTC (World Travel and Tourism Council) (2014) “Country Reports." http://www.wttc.org/focus/research-for-action/economic-impact-analysis/country-reports, accessed December 1, 2014.

Zappalà, G. (2004) "Corporate Citizenship and Human Resource Management: A New Tool or a Missed Opportunity?” Asia Pacific Journal of Human Resources 42: 185-201.

Zoogah, D.B. (2011) "The Dynamics of Green HRM Behaviors: A Cognitive Social Information Processing Approach.” Zeitschrift für Personalforschung 25(2): 117-139. 